\title{
High Geostress Active Fault Zones Geology Tunnel Construction Deformation Monitoring Technology Research
}

\author{
Yongmei Liu \\ Hunan technical college of water resources and hydropower, China \\ liuyongmei998@sina.com
}

Keywords: The high in-situ stress; Deformation monitoring; Advance ductile.

\begin{abstract}
Grew up in deep buried tunnels are often encounter many unfavorable geological conditions, construction of Sichuan songpan project is located in the southern section of minjiang river faulting footwall tunnel on the right side, through the debris flow, landslide and soft rock large deformation DeZhiDai high in-situ stress. By optimizing the project activity fault zone of deformation monitoring in weak rock tunnel, tunnel hole body application advance small duct grouting support; Excavation steps method is used to add temporary inverted arch construction, arch combined hollow bolt, sidewall type bonding mortar anchor, such as the construction process, to effectively control deformation. Provide certain guidance and reference for the similar engineering construction.
\end{abstract}

\section{Engineering Geological Overview}

Songpan Tunnel is located between Songpan County and Chuanzhusi, Aba Tibetan and Qiang Autonomous Prefecture, Sichuan Province. The ground elevation of the tunnel site area is 2900 $3100 \mathrm{~m}$. East-west valleys are more developed because of strong crustal uplift and deep valley, and asymmetric V-shaped valley is formed. Minshan River Valley is located on the left of the tunnel, which is wide and flat, and Songpan County is distributed on the river valley. Jinpan Mountain is located on the right with large elevation difference. Vegetation is not developed well on the mountain slope. Vegetation mainly includes weeds and bushes. Talus slope heap is formed on the foot-slope area, which is mostly reclaimed into dry land. Natural slope is usually $25^{\circ}$ to $35^{\circ}$ with total length of 8048 meters. The maximum depth is 270 meters. Tunnel is located in place 170-600m away from the south section of Minjiang river fault on the right, and footwall of Minjiang river fault. The stratigraphic lithology is mainly composed of Triassic System Pliocene Xinduqiao Formation (T3x) carbonaceous slate splint rock and sandstone. The formation is single, which is affected by Minjiang River Fault. The tunnel passes through soft rock, thereby it is likely to produce large deformation phenomenon. The rock mass on the surface is broken, interlayer extrusion is serious, secondary small fault and soft folds are more developed, thereby leading to large bedding occurrence change.

\section{Difficulties in Project Construction}

Poor Geological Condition and High Safety Pressure. The project is located on the right of southern section of Minjiang River Fault Footwall, which passes through poor sections with large deformation such as debris flow, landslide and soft rock. Unfavorable geology with high ground stress mainly includes landslide, debris flow, harmful gas and high ground stress; Special geotechnical rock and soil include Songpan loess and seasonal frozen earth, which can easily produce collapse with high safety pressure.

High Difficulties in Quality Control. The clearance is reduced after initial support due to easy deformation in the tunnel, thereby leading to initial support beyond limit, subsequent arc replacement and other adverse influence. Initial support is cracked due to too large deformation. The product quality and quantity are guaranteed through systematical research on 'Monitoring and Construction Technology of Tunnel Construction Deformation with High Ground Stress Geology in Active Fault Belt' aiming at characteristics and difficulties in the project. 


\section{Construction Technology}

Construction Plan. Advance support of tunnel body in the work area is grouted and supported by advanced small pipe with diameter of $42 \mathrm{~mm}$. Bench cut method and temporary inverted arch construction are adopted for excavating grade V surrounding rock. Grade IV surrounding rock is constructed by bench cut method. Full-section construction is adopted for grade III surrounding rock. Grade IV and V surrounding rock for initial support is initially sprayed by C30 corrosion-resistant concrete in tunnel excavation. Initial support of excavation is sprayed initially by C25 concrete. Grille and I18 steel frame are adopted for grade IV surrounding rock, I20 section steel frames are adopted for grade $\mathrm{V}$ surrounding rock, $22 \mathrm{~mm}$ combined hollow bolts are adopted for system supporting arc. $22 \mathrm{~mm}$ full-length adhesive mortar anchor rod is adopted. All anchor rods are provided with steel cushion. Steel fiber concrete is sprayed, and radial anchor rod is constructed for reinforcement aiming at some sections with too large deformation.

Construction Method and Technology. Advanced small pipe construction:

(1) Supporting parameters of advanced small pipe construction.

Steel molten pipes are adopted as advanced small pipes with wall thickness of $3.5 \mathrm{~mm}$. Quantity, length and spacing of each ring are shown in Table.1.

Table 1 Parameter table of small pipe advance support

\begin{tabular}{|c|c|c|c|}
\hline Lining type & $\begin{array}{c}\text { Quantity of each ring } \\
\text { (piece) }\end{array}$ & $\begin{array}{c}\text { Longitudinal spacing } \\
(\mathrm{m})\end{array}$ & Single piece length (m) \\
\hline Grade V shock resistance & 38 & 3 & 4.5 \\
\hline Grade V reinforcement & 38 & 3 & 4.5 \\
\hline $\begin{array}{c}\text { Grade V compound and } \\
\text { non-insulation general anchor section }\end{array}$ & 38 & 3.2 & 4.5 \\
\hline $\begin{array}{c}\text { Grade V compound and } \\
\text { non-insulation lower anchor section }\end{array}$ & 40 & 3.2 & 3.5 \\
\hline $\begin{array}{c}\text { Grade IV compound and } \\
\text { non-insulation general anchor section }\end{array}$ & 30 & 2.4 & 3.5 \\
\hline $\begin{array}{c}\text { Grade IV compound and } \\
\text { non-insulation lower anchor section }\end{array}$ & 32 & 2.4 & \\
\hline
\end{tabular}

(2) Construction technological flow of advanced small pipe

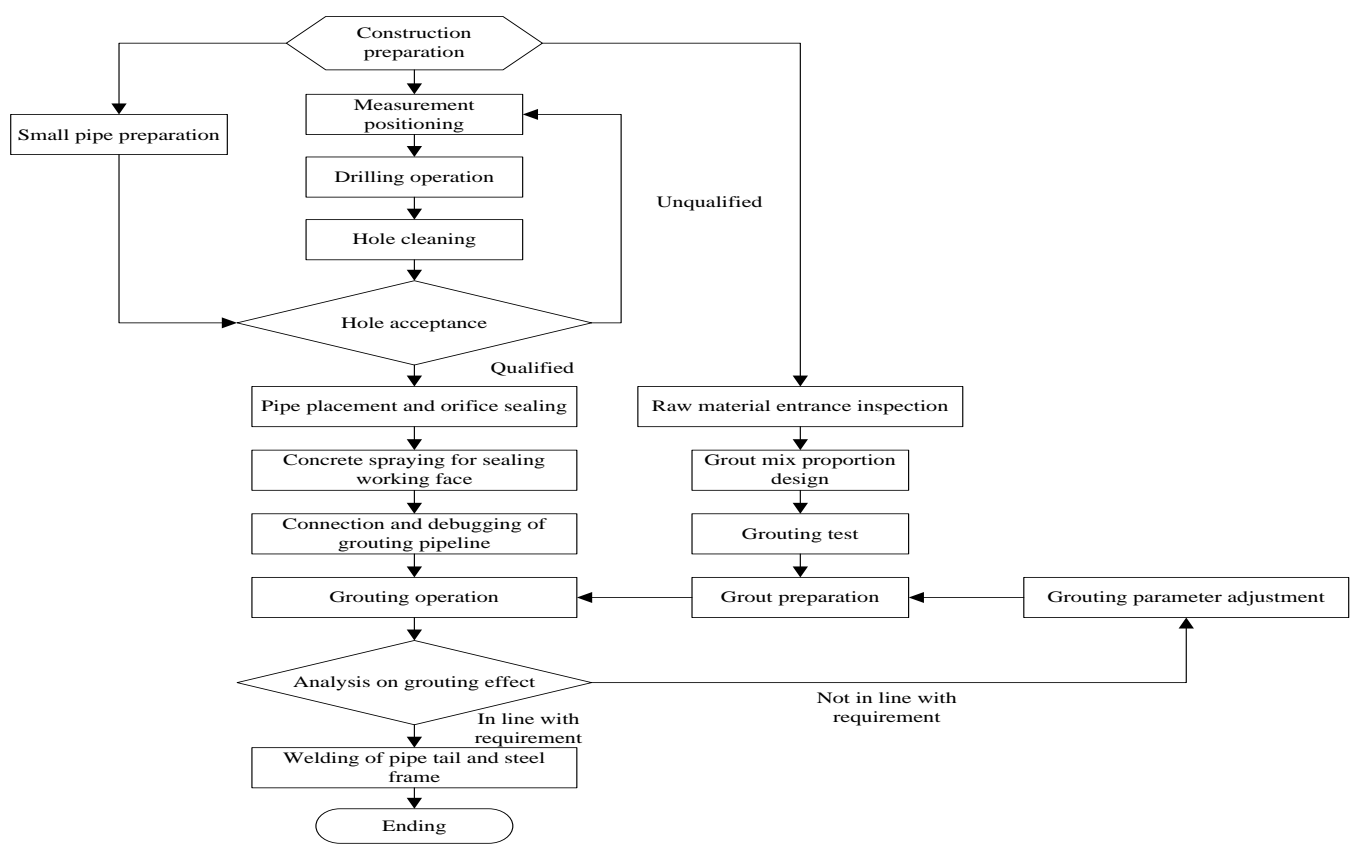

Figure 1. Construction tecnological flowchart of advanced small pipes 
(3) Construction method.

Concrete is sprayed for sealing tunnel face before construction of advanced small pipes. Then, small pipes are grouted for forming reinforced ring with certain thickness, excavation is implemented, etc.

Small pipes are manufactured in component processing factory. The front end is made into cone shape. $\varphi 8 \mathrm{~mm}$ steel bar stiffening ring is welded on the tail. Holes are drilled on the pipe wall in a staggered mode every $15 \mathrm{~cm}$, and the hole diameter is $6 \sim 8 \mathrm{~mm}$. Before small pipes are punched, the positions of small pipes should be drawn according to design requirements. Numbers should be labeled. After pneumatic rock drill is used for punching, small pipes are inserted into holes according to design requirements. Small pipes are driven along middle part of the steel frame directly by free hammer or rock drill in sections with weak surrounding rock. The tail part is welded with steel frame together for jointly forming pre-support system. The orifice hole deviation is less than $5 \mathrm{~cm}$. The hole length is greater than the length of small pipes. The small pipes are driven then, and high pressure wind is adopted for blowing out sand, stone and other debris in the small pipe after the small pipes are driven. The orifice and surrounding rock cracks outside the pipe are sealed by plastic mud after small pipes are installed.

Grouting pump is adopted for grouting, and cement single-fluid grout is grouted. Rational grouting parameters are determined during construction according to field test. Cement slurry mix proportion is determined according to test, and the following requirements should be met: slurry has excellent liquidity, which can be easily injected into formation; the slurry has low shrink after consolidation, good adhesive power and higher early strength; Stone body has low permeability, excellent anti-permeability performance, etc.

Stop-grouting plug is set at the orifice. Free holes should be firstly grouted, and then holes with water should be grouted then. Pipes should be grouted one by one from arch foot to vault. Slurry should be grouted with interval of one hole or several holes in case of slurry mixing or slurry leakage. The grouting process should be recorded by special personnel. The effect is checked after grouting is ended, and grout should be complemented in unqualified holes.

Small pipe grouting process parameters: cement slurry is adopted. Ordinary Portland cement is applied, wherein water cement ratio of cement slurry is $1: 1$. Dosage of accelerator is $3 \sim 5 \%$. The grouting pressure is $0.5 \sim 2.0 \mathrm{Mpa}$.

Small pipe grouting quantity is calculated according to the following formula: $\sigma=\pi \times R^{2} \times L \times n \times K$

In the formula:

$\mathrm{R}$ - grout diffusion radius, and it is considered according to $0.25 \mathrm{~m}$;

L-small pipe length;

$\mathrm{n}$ - porosity of rock mass;

$\mathrm{K}$ - filling coefficient, the value is $0.3 \sim 1.0$, smaller value is adopted for silty clay, and larger value is adopted for gravel soil and sandy soil.

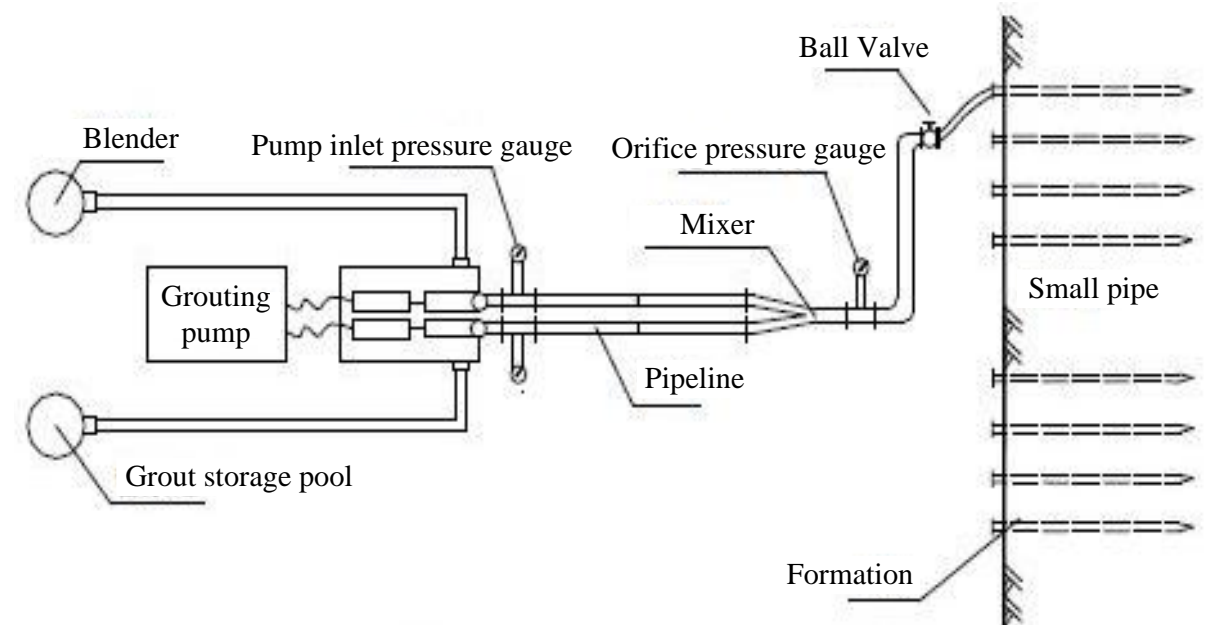

Figure 2. Small pipe grouting process sketch map 
Concrete is sprayed firstly for 5 to $10 \mathrm{~cm}$ before grouting, thereby sealing the tunnel face as blocked concrete wall. When single-hole grouting quantity reaches the designed grouting quantity, grouting is completed. Grouting parameters should be adjusted according to grouting test results and site condition. Grouting records should be seriously filled during grouting operation, and operation can be analyzed and improved at any time. The state of construction support working faces should be observed. The tunnel face should be excavated before excavation. Excavation operation should be implemented when there is no prominent water seepage.

Tunnel Excavation. Self-bearing capacity of the surrounding rock should be protected by all measures during tunnel excavation. Smooth blasting, non-blasting mechanical auxiliary excavation method, etc. should be adopted. Drill hole quality should be based on stricter requirements. Designed blast hole positions can be marked on the working face before drilling, thereby ensuring correct implementation. However, the work is not seriously implemented because the construction site is lack of suitable measurement facilities, which should be highly emphasized. Tools are prepared for ensuring protection. Therefore, designed blasting effect can be reached. Blast-hole trace survival rate should not be less than $80 \%$ for hard rock and not be less than $60 \%$ for medium hard rock. The traces are evenly distributed on the excavation contour.

(1) Excavation contour shape and section size must comply with design requirements

Over-cut and undercut should be strictly controlled. Firstly, it is stressed that under-cut is not allowed. Secondly, when the surrounding rock is complete, and stone mass is hard, protruded part (not larger than $0.1 \mathrm{~m} 2$ for each $1 \mathrm{~m} 2$ ) of some rocks penetrate into the lining for less than $5 \mathrm{~cm}$. Under-cut is not allowed in the scope $1 \mathrm{~m}$ above the arch support and wall foot. Excavation elevation of side wall foundation and tunnel bottom should be in line with design requirements, especially the side wall foundation depth should not be under-cut, and influence of insufficient side wall foundation embedding depth on overall stress condition of tunnel structure should be avoided.

(2) Bench cut method is adopted for grade IV and V surrounding rock section, and the sections should be consistent with the following regulations:

(1) Footage of excavation support on grade V surrounding wall should not be larger than spacing of one steel frame on the step for each cycle. Grade IV surrounding wall should not be larger than the spacing of two steel frames.

(2) The excavation support footage of side wall should not be larger than two frames for each cycle.

(3) Before inverted arch is excavated, steel frame locking anchor rod should be completed, and excavation footage should not be larger than $3 \mathrm{~m}$ for each cycle.

(4) The initial support should be timely constructed and sealed into ring after tunnel excavation. The distance from the grade $\mathrm{V}$ surrounding rock sealed position to the tunnel face should not be larger than $30 \mathrm{~m}$. The distance from the IV surrounding rock sealed position to the tunnel face should not be larger than $35 \mathrm{~m}$, and the distance from III surrounding rock sealed position to the tunnel face should not be larger than $50 \mathrm{~m}$.

(3) Various excavation methods are adopted according to surrounding rock grade and surrounding environment

Bench cut method is adopted for constructing grade IV surrounding wall in the tunnel body. Bench cut method and temporary inverted arch method are adopted for constructing grade $\mathrm{V}$ surrounding wall section. The upper step height is about $6 \mathrm{~m}$ and the lower step height is $4.5 \mathrm{~m}$ during construction by bench cut method.

Construction patterns of advance support, excavation, early support, inverted arch filling, secondary lining, accessory work balanced production, and overall advancement is formed in construction. Initial supports of fault fracture zone and the influence zone are timely formed into rings. Secondary lining is timely constructed according to surrounding rock measurement results.

Bench cut method is adopted for constructing grade IV and V surrounding rock sections. The grade $\mathrm{V}$ surrounding rock of excavation support on each step should not be larger than the spacing of one steel frame for each cycle. The grade IV surrounding rock should not be larger than the spacing of two 
steel frames. The steel frame spacing of grade V surrounding rock grille (I-shaped steel) should be $0.6 \mathrm{~m}$. The steel frame spacing of grade IV surrounding rock grille (I-shaped steel) should be $0.8 \mathrm{~m}$. The side wall excavation footage should not be larger than spacing of two steel frames for each cycle. Steel frame locking anchor rods must be completed before inverted arch excavation. The excavation footage should not be larger than $3 \mathrm{~m}$ for each cycle.

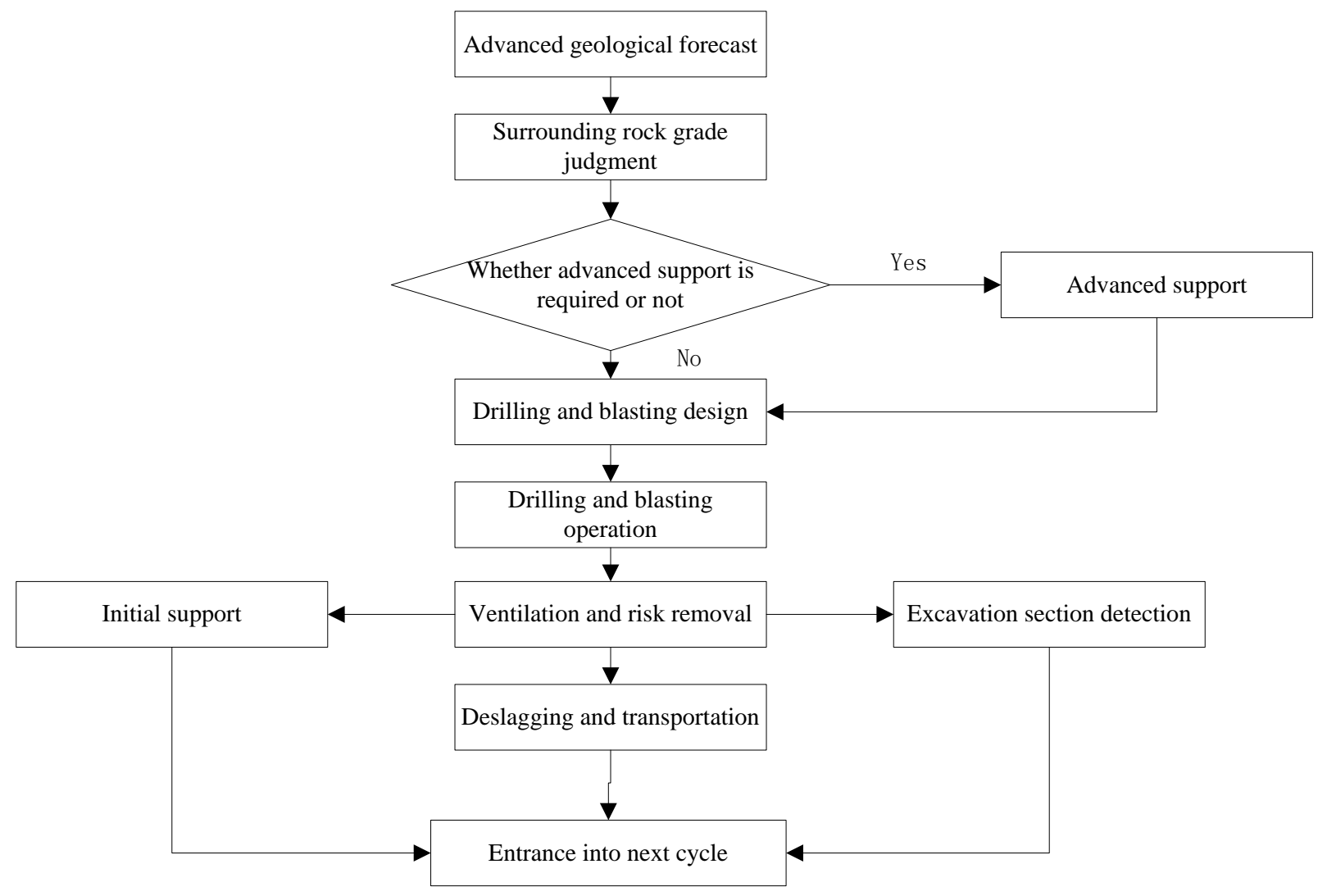

Figure 3. Tunnel section excavation construction process flowchart

Construction by Bench Cut Method and Temporary Inverted Arch Method. When bench cut method and temporary inverted arch method are adopted for excavation, suitable step length can be reserved according to concrete condition, one right is excavated, and one ring is supported, temporary inverted arch should be timely constructed after excavation on the lower section, thereby forming sealed structure.

Advanced small pipes are adopted for initial support. Weak blasting is adopted for upper drift heading. Control blasting excavation is adopted for lower drift heading and inverted arch, thereby protecting surrounding rock. After all parts are excavated, tunnel face should be timely sealed. Spraying, network, anchor and section steel frame are combined for supporting operation. Temporary inverted arch can be produced. Locking anchor pipes are additionally set for arch foot, and wall feet of upper and lower steps. Initial support can be timely formed into rings. Pneumatic rock drill is adopted for drilling holes. Non-electric millisecond detonators are adopted for short-delay blasting. Electric detonator is adopted for detonating, and wet spraying machine is adopted for wet spraying operations in gas area. Construction length of inverted arch is $3 \mathrm{~m}$. Parallel operation is implemented in each part.

Surrounding rock should be measured seriously during construction. Informatization construction and dynamic management are implemented. Information should be timely fed back. Supporting parameters are adjusted, removal time of temporary inverted arch should be determined, thereby ensuring construction safety. Construction and water pumping are reinforced in the tunnel, thereby preventing instability of side wall. 


\section{Conclusion}

Deformation monitoring construction technology of tunnel with high ground stress geology in active fault zone is applied in Songpan tunnel construction. Tunnel deformation is effectively controlled. The deformation over-limit rate from the control point is reduced from $21 \%$ to $4 \%$, thereby accelerating site construction progress, and providing effective guarantee for site safety construction. Monitoring measurement data is combined for adjusting site deformation allowance in real-time, ensuring material saving and accelerating construction progress. Cost of 500 Yuan $\times 8048=4.024$ million Yuan can be served if subsidence is reduced by each $5 \mathrm{~cm}$ on average. Economic and social benefits are remarkable with good promotion and application value.

\section{References}

[1] Wang Jiaxiang, Shi Cunpeng. Research on tunnel surrounding rock stability of some large water diversion tunnel passing through fault zone People Yangtze River, 2015, (14).

[2] Li Xuefeng, Dai Zhiping. Influence of deformation crack spacing on internal force of the tunnel under active fault alternate displacement Tunnel Construction, 2014. (3).

[3] Wu Haishan. Several methods of tunnel construction fore shaft under bad geological condition.Journal of Changjiang Institute of Technology, 2009. (1).

[4] Qiu Yongchun. Treatment of hydraulic tunnel construction landslide under poor geological conditions Science and Technology Innovation and Applications, 2015 (13).

[5] Ye Shengjiao. Construction and review of the Simplon rail tunnel. Railway Engineering Construction Division level dynamic Report Series - Railway Tunnel and Underground Engineering. Southwest Jiaotong University Press, 1995, 120-134.

[6] Wang Ke. The geological conditions and stress characteristics of Jiazhuqing tunnel. World dangerous road,1999,(1): 11-16

[7] Tao G, King M S. Shear-wave velocity and Q anisotropy in rocks: A laboratoiystudy. International Journal of Rock Mechanics and Mining Science \& Geomechanics Abstracts, 1990, 27(5): 353-361.

[8] Homand F, Morel E, Hemy J P, et al. Characterization of the module of elasticity of an anisotropic rock using dynamic and static methods. International Journal of Rock Mechanics and Mining Science \& Geomechanics Abstracts, 1993, 30(5): 527-535.

[9] Peter B Attewell \& Michael R Sandford, Intrinsic shear strength of a brittle, anisotropic rock: textural data acquisition and processing. International Journal of Rock Mechanics and Mining Science \& Geomechanics Abstracts, 1974, 11(11): 431-438.

[10] Guan Baoshu,Zhao Yong. Soft and weak rock tunnel construction technology. China Communications Press, 2011. 